\title{
SENSITIVITAS SENSOR MLX90614 SEBAGAI ALAT PENGUKUR SUHU TUBUH TUBUH NON-CONTACT PADA MANUSIA
}

\author{
Yanuar Mukhammad ${ }^{1}$, Agoes Santika Hyperastuty ${ }^{2}$ \\ ${ }^{1}$ Prodi D-III Teknik Elektromedis Universitas Kadiri \\ ${ }^{2}$ Prodi D-III Teknik Elektromedis Universitas Kadiri \\ Alamat Korespondensi : Prodi D-III Teknik Elektromedis \\ Jl. Selomangkleng No.1 Kota Kediri, JawaTimur, Indonesia \\ Email :santika@unik-kediri.ac.id
}

\begin{abstract}
ABSTRAK
Sensor suhu tubuh non-contact sangat penting bagi manusia untuk mengukur suhu tubuh secara cepat dan praktis. Salah satu sensor yang dapat dipakai untuk mengukur sensor suhu tubuh non-contact adalah MLX90614. Sensor MLX90614 memiliki memiliki dua buah ouput yaitu suhu ruangan dan suhu object. Sensor Modul MLX90614 memiliki chip detektor thermopile sensitif IR dan ASIC pengkondisi sinyal terintegrasi dalam packing sensor model TO-39. Pengkondisi sinyal berupa low noise amplifier, 17-bit ADC dan unit DSP yang kuat sehingga mencapai akurasi dan resolusi tinggi dari termometer. Sensor dikalibrasi dengan output SMBus digital yang diukur dalam kisaran suhu lengkap dengan resolusi $0,02^{\circ} \mathrm{C}$. Sensor dapat mengukur Suhu -40 hingga $125^{\circ} \mathrm{C}$ untuk suhu ruangan dan -70 hingga $380^{\circ} \mathrm{C}$ untuk suhu objek. Berdasarkan percobaan dari suhu 26 ${ }^{\circ} \mathrm{C}$ sampai $40{ }^{\circ} \mathrm{C}$ Tingkat error sensor MLX90614 pada jarak sensor dengan object adalah $3-5 \mathrm{~cm}$ adalah $0-2 \%$ dengan error suhu yang dihasilkan adalah $+-2{ }^{\circ} \mathrm{C}$ dari kalibrator sensor suhu tubuh menggunakan thermocouple sehingga sensor MLX90614 bisa digunakan untuk mengukur suhu object baik itu manusia atapun benda secara non-contact.
\end{abstract}

Kata kunci: sensor, suhu tubuh

\section{ABSTRACT (TNR11)}

Non-contact body temperature sensors are very important for humans to measure body temperature quickly and practically. One of the sensors that can be used to measure non-contact body temperature sensors is the MLX90614. The MLX90614 sensor has two outputs, namely room temperature and object temperature. Sensor Module MLX90614 has IR sensitive thermopile detector chip and signal conditioning ASIC integrated in the sensor packing of the TO-39 model. The signal conditioner is a low noise amplifier, 17-bit ADC and a powerful DSP unit that achieves high accuracy and resolution from the thermometer. The sensor is calibrated with a digital SMBus output measured in a complete temperature range with a resolution of $0.02{ }^{\circ} \mathrm{C}$. The sensor can measure Temperature -40 to $125^{\circ} \mathrm{C}$ for room temperature and -70 to $380^{\circ} \mathrm{C}$ for object temperature. Based on experiments from a temperature of 26 oC to $40 \mathrm{oC}$, the MLX90614 sensor error rate at the distance of the sensor to the object is $0-2 \%$ with the resulting temperature error is +-2 oC from the body temperature sensor calibrator using a thermocouple so that the MLX90614 sensor can be used to measure the temperature of objects, be it humans or non-contact objects.

Keywords : sensor, body temperature

\section{PENDAHULUAN}

Dimasa pandemi sensor suhu tubuh sangat penting sekali untuk manusia dikarenakan salah satu indikasi orang yang demam adalah naiknya suhu tubuh diatas normal (2). Salah satu ensor yang bisa digunakan untuk mengukur object dan suhu $\begin{array}{lll}\text { tubuh adalah MLX90614 (2).Sensor } & \end{array}$ MLX90614 memiliki ukuran yang kecil dan biaya rendah sehingga harga jual alat bisa 
rendah (3). Sensor ini mengukur secara Non Contact sehngga praktis dan mudah digunakan. Sensor ini mudah diintegrasikan ke beberapa macam alat seperti mikrokontroller atau mikroprocessor. Kelebihan lain dibanding sensor lain yaitu akurasinya yang bagus dan waktu pengukuran lebih cepat (4) yaitu kurang dari 1 menit sudah muncul nilai hasilnya. Untuk mengukur suhu tubuh bisa juga menggunakan sensor thermocouple yang ditaruh diketiak namun butuh waktu yang lumayan agar didapat nilai hasil pengukurannya maka dari itu solusinya adalah menggunakan sensor suhu tubuh noncontact yang memiliki kecepatan pengukuran yang lebih cepat dari bentuk thermocouple.

\section{METODE}

Metode pengukuran yang dilakukan untuk pengujian sensor adalah menggunakan metode kalibrasi secara linier dengan mengambil 29 data secara realtime dengan jarak sensor ke object $3 \mathrm{~cm}$ sampai $5 \mathrm{~cm}$. Object benda panas yang dikukur menggunakan sebuah solder yang ditaruh tepat diatas sensor lalu kalibrator juga ditaruh didekat sensor sehingga bisa diketahui nilai akurasi dan sensitifitas keduanya. Kalibrator yang digunakan adalah thermometer suhu tubuh menggunakan thermocouple.

\section{HASIL DAN PEMBAHASAN}

Percobaan dilakukan pada suhu ruangan dan menggunakan object panas yang dapat di naik turunkan panasnya sehingga terlihat tingkat sensitifitas dari masing- masing sensor. Berikut adalah hasil percobaan yang dilakukan.

Tabel 1. Experiment between MLX90614 and kalibrator

\begin{tabular}{|c|c|c|}
\hline $\begin{array}{l}\text { MLX90614 } \\
{ }^{\circ} \mathrm{C} \\
\end{array}$ & $\begin{array}{c}\text { Thermocouple } \\
{ }^{\circ} \mathrm{C}\end{array}$ & Error \% \\
\hline 29,9 & 29,9 & 0 \\
\hline 33,7 & 33.6 & 0,29 \\
\hline 27,3 & 27,6 & 1,09 \\
\hline 27 & 27,1 & 0,37 \\
\hline 26,6 & 26,5 & 0,37 \\
\hline 38,2 & 38,1 & 0,26 \\
\hline 36,5 & 36,9 & 1,09 \\
\hline 30,5 & 30,3 & 0,65 \\
\hline 29,8 & 29,8 & 0 \\
\hline 29,5 & 29,1 & 1,35 \\
\hline 29 & 28,5 & 1,72 \\
\hline 28,5 & 28,3 & 0,70 \\
\hline 28,2 & 27,7 & 1,77 \\
\hline 28,3 & 27,5 & 2,82 \\
\hline 26,3 & 26,7 & 1,52 \\
\hline 40,6 & 40,1 & 1,23 \\
\hline 34,8 & 34,4 & 1,14 \\
\hline 33,7 & 33,9 & 0,59 \\
\hline 32,7 & 32,8 & 0,30 \\
\hline 31,9 & 31,7 & 0,62 \\
\hline 30,3 & 30,2 & 0,33 \\
\hline 29,8 & 29,6 & 0,67 \\
\hline 29,4 & 29,3 & 0,34 \\
\hline 28,9 & 28,8 & 0,34 \\
\hline 28,6 & 28,3 & 1,04 \\
\hline 27,2 & 27,8 & 2,20 \\
\hline 27 & 27,3 & 1,11 \\
\hline 26,5 & 26,8 & 1,13 \\
\hline 29,9 & 29,9 & 0 \\
\hline
\end{tabular}

Pada hasil percobaan terlihat persen error dari sensor MLX90614 dibanding dengan sensor thermocouple paling tinggi adalah 2,8 \% yang mana \% error lebih dari $2 \%$ itu terjadi hanya beberapa kali saja didalam pengukuran dan lebih dominan dirange error $0-1 \%$. Persen error yang tinggi terjadi akibat jenis sensor yang dipakai berbeda sehingga waktu respon juga berbeda. 


\section{KESIMPULAN}

Bahwa sensor MLX90614 memiliki tingkat akurasi yang bagus untuk mengukur suhu tubuh manusia atau benda secara non-contact dikarenakan \% error yang didapat hanyalah $2,8 \%$ dari sensor kalibrator yang berupa thermocouple. Sensor MLX90614 juga memiiki waktu sampling suhu yang cepat sehingga hanya memerlukan waktu dalam ms untuk mendapatka hasilnya.

\section{DAFTAR PUSTAKA}

Jin, G., Zhang, X., Fan, W., Liu, Y., \& He, P. (2015). Design of non-contact infrared thermometer based on the sensor of MLX90614. The Open
Automation and Control Systems Journal, 7(1).

Nn-digital (2019). Spesifikasi MLX90614. https://www.nndigital.com/blog/2019/06/16/belajarprogram-sensor-suhu-non-contactir-infra-red-gy-906-mlx90614dengan-arduino. Diakses pada tanggal 6 Februari 2021

Xiahou, K. S., Zeng, X. J., Hu, L. K., Li, G. P., \& Ye, R. H. (2011). Design of human-body temperature monitoring system based on MLX90614 and ZigBee. Automation and instrumentation, 11, 23-26.

ZHENG, G. L., \& LIU, L. S. (2014). Noncontact Thermometer Based on MLX90614. Automation \& Instrumentation, 10.

ZHONG, J., CAI, L. M., \& YU, Y. (2015). Design of wireless temperature acquisition system based on MLX90614. Transducer and Microsystem Technologies, 03. 